\title{
Ciência e negacionismos: pelo menos um $X$ das questões
}

\author{
Science and denialism: at least one crux of the matter
}

Ciencia y negacionismo: al menos un punto crucial

de los problemas

Recebido em 25-05-2021

Modificado em 30-06-2021

Aceito para publicação em 24-07-2021

\section{doi https://doi.org/10.47456/simbitica.v8i3.36810}

\section{Ivan da Costa Marques}

Engenheiro Eletrônico, Instituto Tecnológico de Aeronática (ITA). Ph.D, Electrical Engineering and Computer Science, University of California, Berkeley Visiting Scholar no Historical Studies Committee da New Scholl for Social Research, New York (1990-1992). Professor do Programa de Pós-Graduação em História das Ciências e das Técnicas e Epistemologia da Universidade Federal do Rio de Janeiro. Email: imarques@nce.ufrj.br

\section{Resumo}

Os estudos sociais das ciências e das tecnologias, ao mostrarem os conhecimentos científicos como obras humanas, abriram, por um lado, novas possibilidades de convívio pacífico com "modos de vida" estranhos às ciências, mas, por outro lado, oportunidades para os negacionismos. A dificuldade é que o abandono da ilusão dos conhecimentos científicos como universais, neutros e objetivos de forma absoluta visava o fortalecimento e não o enfraquecimento dos conhecimentos científicos. Mas o fim da ilusão propiciou oportunidades permanentes de aberturas de controvérsias. Surgiram então execráveis "mercadores da dúvida" que, com recursos, apostam na desqualificação dos conhecimentos científicos e dos cientistas. Como tratar o fim da ilusão absolutista da Ciência e não jogar fora os conhecimentos científicos? Essa é a questão que pretendo abordar.

Palavras-chave: Ciência; negacionismo; conhecimento; euro-americano. 


\section{Introdução}

Com boas razões, pode-se hoje duvidar dos benefícios da "Humanidade" como um atrator que nos junta a todos ${ }^{1}$. A materialidade, no entanto, impõe a discussão de um mundo parcialmente comum: toda a Humanidade habita o mesmo planeta. Pode-se também dizer que tanto a Humanidade quanto a própria compreensão de planeta são constructos ou concepções eurocêntricas, e certamente são. Mas dizer isso não evita uma questão crucial de governança realçada e apressada pela pandemia Covid-19: que saberes e conhecimentos devemos levar em conta e tomar como legítimos para que possamos, sem genocídios, compartilhar parcialmente nossas vidas e os espaços em que vivemos? ${ }^{2}$

Digo que a busca é por um mundo parcialmente comum porque os povos ameríndios, por exemplo, estão tão longe de desejar o modo de vida do homem branco, o "povo da mercadoria", quanto este está longe de desejar os modos de vida dos povos ameríndios (Kopenawa; Albert, 2015). A busca é por um mundo parcialmente comum porque sempre haverá diferenças a serem preservadas, partes não compartilhadas, mundos à parte e, em benefício da diversidade, é bom que seja assim. A negociação do mundo comum será para as localidades não necessariamente geográficas onde diferentes modos de vida necessariamente interagem, localidades que, emprestando o termo de Mary Louise Pratt, denomino "zonas de contato".

Ao nos aproximarmos da questão da governança em zonas de contato logo nos deparamos com o perigo de cair numa armadilha: a armadilha de crer saber como os outros devem viver. Quando escrevo "nós” quero dizer pessoas bastante escolarizadas como são, suponho, as leitoras deste artigo. A parte escolarizada da população brasileira, mesmo aquela parte dela que é, digamos, bem-intencionada, à esquerda ou à direita, especialmente aquela parte que se interessa ou lida diretamente com questões de governança, cai com frequência na armadilha de crer saber como os outros devem viver. Isto é, até certo ponto, esperado porque é uma das lições aprendidas em nossas escolas: o que se ensina na escola, especialmente a ciência que a escola ensina, é conhecimento e o resto é crença - e, adicionalmente, segundo o que

\footnotetext{
1 "Quem sabe a própria ideia de humanidade, essa totalidade que nós aprendemos a chamar assim, venha a se dissolver com esses eventos que estamos experimentando (Krenak, 2020:13). "Os constructos 'raça' e 'humanidade', elementos que fundamentam uma alteridade produtora de desigualdades e injustiças, devem ser enfrentados, transgredidos e transmutados perspectivando novos atos de responsabilidade com a vida em toda a sua esfera" (2019:16). Ver também (Sahlins, 2008).

2 "Sugere-se que para evitar outras crises no futuro será necessário modificar o imaginário político mundial. Será preciso aceitar a ideia de que moramos todos no mesmo planeta e devemos nos tornar uma comunidade política mundial" (Nascimento, 2020b:39).

3 “O termo 'zona de contato' procura enfatizar as dimensões interativas e improvisadas dos encontros coloniais tão facilmente ignoradas ou suprimidas pelos relatos de conquista e dominação. Uma 'perspectiva de contato' põe em relevo a questão de como os sujeitos são constituídos nas e pelas suas relações uns com os outros" (Pratt, 1992/1999:32).
} 
aprendemos na escola, o conhecimento é superior à crença. Impregnados que somos com mais de 12 anos de escolaridade, é esperado que tenhamos dificuldade em não naturalizar como atrasado ou não descartar como ignorância o conhecimento daqueles que não frequentaram e não se expuseram a essa escola e/ou não aderiram ao modo de vida que a parte dominante da escola colonizadora ("mainstream") ainda insiste em difundir.

Neste momento de urgência e tragicidade na busca de governanças para enfrentar a crise sanitária aguçada no Brasil pela Covid-19, o conhecimento científico coloca-se como aquele conhecimento que deve dizer como todos devem viver. Como poderia ser diferente, se o conhecimento científico é, evidentemente, acredita-se, o conhecimento mais confiável de que dispõe a Humanidade? Diante de tamanha evidência causa espanto e/ou indignação a resistência dos negacionismos, do criacionismo, do terraplanismo ou da receita da Cloroquina. Adianto que não vou propor o descarte dos conhecimentos científicos, estou muito longe disso. Mas o restante deste capítulo versa em torno dessa reação espantada/indignada do público cientificamente informado diante das resistências à Ciência no comando da governança. Como, simultaneamente, respeitar os conhecimentos científicos e respeitar os que chegam resistindo à Ciência?

\section{Humildade: da Ciência às ciências, com cuidado!}

A Ciência é uma pedra de toque da modernidade euro-americana. Apesar disso, e talvez por causa disso, um tanto ironicamente, foi justamente na Europa e nos EUA que, pincipalmente a partir da segunda metade do século XX, olhares empíricos se voltaram reflexivamente para a própria Ciência. (Bijker et al., 1987) São bastante conhecidos os estudos de laboratório iniciais, das décadas 1970 e 1980. Cientistas sociais antropologicamente informados entraram nos laboratórios e estudaram etnograficamente como físicos e biólogos pesquisavam e estabeleciam seus conhecimentos científicos. Esses estudos antropológicos abordaram os cientistas e os laboratórios da maneira que os antropólogos abordavam os "povos primitivos" desde o século XIX, observando e anotando exaustiva e simultaneamente tanto o que eles diziam como o que eles faziam. Era a primeira vez que a vida dos cientistas nos laboratórios foi observada. Eles tornaram-se, por assim dizer, de forma um tanto imperfeita, objetos e não mais só sujeitos do conhecimento. Até então os cientistas encenavam o "truque do olho de Deus" ("God's eye trick"), isto é, podiam potencialmente ver tudo e não eram vistos por ninguém ${ }^{4}$.

\footnotetext{
${ }^{4}$ São quatro os mais famosos estudos de laboratório dessa época: Latour e Woolgar (1986), Lynch (1985), KnorrCetina (1981), Traweek (1988). Destes, somente o primeiro está traduzido para o português. A expressão “God's eye
} 
Esse privilégio de tudo poder ver sem ser visto, usufruído pela Ciência, ou melhor, pelos cientistas, decorre de uma separação epistemológica radical entre um sujeito para conhecer e um objeto para ser conhecido. Esta separação epistemológica enseja, ontologicamente, a existência da/o cientista como um sujeito muito especial. O cientista não só não precisa como não deve se apresentar como alguém de carne e osso, justamente porque o objeto que ele conhece tem uma pureza que independe totalmente dele. Estamos convencidos, é evidente, que a gravidade, uma vez estabelecida como conhecimento científico, independe das peculiaridades da vida de Newton, assim como o oxigênio independe de Lavoisier e a vacina contra a poliomielite de quem era Jonas Salt. Afinal, se assim não fosse, nem a gravidade, nem o oxigênio, nem a vacina seriam objetos científicos. Até a virada antropológica dos estudos de laboratório indicados acima, esta façanha da Ciência era sustentada por uma tradição do enquadramento epistemológico do conhecimento científico, ou melhor, do apagamento desse enquadramento, mas voltaremos a isso adiante. Acontece que essa façanha não deixava, no entanto, de transpor os muros dos departamentos de filosofia das universidades para chegar à sociologia da ciência e daí mais facilmente partir para a grande imprensa e o grande público. E a sociologia da ciência, até um pouco depois de meados do século XX, difundiu uma imagem do mundo onde residia e trabalhava o cientista desencarnado e poderoso, esse alguém que pode tudo observar e explicar, mas sobre quem não se precisa saber rigorosamente mais nada.

O famoso sociólogo americano Robert K. Merton escreveu sobre e quando a Ciência ainda estava no ápice do prestígio, devido justamente ao seu papel no desfecho da Segunda Guerra (Calhoun, 2010). Uma parte de sua obra atingiu um público mais amplo e de maneira difusa, marcando quatro valores idealizados como elementos característicos daquele mundo da Ciência:

\footnotetext{
"Comunalismo" (a palavra original de Merton era "comunismo"): o conhecimento científico é um bem comum, é uma conquista que pertence à Humanidade; os cientistas renunciam à propriedade intelectual em troca de reconhecimento e estima;

"Universalismo": as verdades são avaliadas em termos de critérios universais ou impessoais, e não influenciados por raça, classe, gênero, religião ou nacionalidade;

"Atuação desinteressada": o cientista não se submete a qualquer interesse egoísta e é movido exclusivamente pela busca da verdade; é imoral esconder informação que pode ser de grande importância para outros; o conhecimento científico é visto como um retorno do investimento feito pela sociedade;

"Ceticismo organizado": todas as ideias precisam ser testadas e estão sujeitas ao escrutínio rigoroso e estruturado da comunidade; a ciência descobre verdades e leis que estão previamente dadas na Natureza (Merton, 1970:53-62).
}

trick" ("truque do olho de Deus") veio mais tarde no âmbito dos estudos feministas das ciências e das tecnologias. Ver especialmente (Haraway, 1991). 
Sua obra tem as marcas, preocupações, e limitações daquela época. Após a entrada da antropologia nos laboratórios, as idealizações de Robert K. Merton foram duramente criticadas e são hoje arcaicas, assim como a convicção de que a Ciência produz objetos "puros" (Marcovich; Shinn, 2011; Shapin, 2010; 2013) Embora hoje arcaicas para os especialistas, as idealizações mertonianas do cientista como um mocinho incorruptível permanecem ainda fortes no imaginário leigo, na grande imprensa e no grande público. Além disso, ou justamente por isso, a separação entre o "científico" ou "técnico" e o "político" é todos os dias usada politicamente, mobilizando sub-repticiamente a ideia de um mundo científico esvaziado de política. As declarações "isso é uma questão científica" ou "isso é uma questão técnica" que lemos ou ouvimos diariamente nos jornais e na televisão são afirmações políticas. Elas querem dizer que a questão em pauta deve ficar a cargo de um grupo de especialistas e ser resolvida por eles, desqualificando de imediato todos os outros para participar da discussão da tal questão. O grande público, tanto no Brasil quanto em outros países, está muito distante da virada antropológica dos anos 1970/80 e permanece com a visão da Ciência idealizada por Merton. Isso fortalece a crença que a Ciência, sem maiores qualificações, justamente porque é capaz de estabelecer conhecimentos nesse mundo mertoniano incorruptível que independe das peculiaridades e interesses pessoais, sabe como cada um e os outros devem viver.

Os cientistas interpõem grandes dificuldades ao exercício da fraude e da corrupção, a ponto de com razão se dizer que "nas ciências a fraude é uma homenagem do vício à virtude." (Latour, [1987] 1997:83). Não é preciso, no entanto, negar isso para mostrar que o mundo da Ciência, tal como ensejado pela obra de Merton, nunca existiu. O acompanhamento minucioso da gênese e desenvolvimento de fatos científicos revelou que um conhecimento científico é o resultado estabilizado de um longo processo de ajuste e justaposição de elementos heterogêneos, envolvendo uma cadeia de decisões e opções que é esquecida ou apagada ao se atingir uma situação satisfatoriamente estabilizada. Essa cadeia de decisões e opções configura o enquadramento do conhecimento científico que dela resulta. É precisamente assim, apagando essa cadeia de vínculos entre o conhecimento e quem, o quê, quando, onde e em que condições ele foi gerado e desenvolvido, que se fortalece a crença de que o conhecimento científico vale independentemente de seu enquadramento e não é restrito a um recorte material, histórico, social, cultural, ganhando assim a transcendência de valer em todos os tempos e lugares. Aquela situação satisfatoriamente estabilizada, final embora sempre provisional, uma vez apagadas as contingências que levaram a ela, é anunciada como a descoberta de uma verdade da Natureza, portanto uma verdade independente da Sociedade e, a partir daí, independente da própria Humanidade. Nessa perspectiva (epistemológica e ontológica), a ciência descobre objetos que 
“estão lá” na Natureza, por assim dizer, haja ou não humanos no universo. Com o apagamento das decisões que levaram a ele, o fato científico apresenta-se aos humanos como universal, neutro e objetivo, desenquadrado, não situado.

A visão de Robert K. Merton sobre a Ciência pode ser admirável e cativa muita gente, mas o eminente sociólogo não entrou no laboratório para estudar o que acontece lá. Ele contemplou fatos científicos já prontos, isto é, já sem suas cadeias de vínculos, e simplesmente imaginou um mundo ideal que os produziria. Vejamos exemplos da vida nos laboratórios, parte crucial do mundo em que os fatos científicos são criados.

Ludwik Fleck fez, ainda na primeira metade do século XX, uma descrição inaugural e magistral da "gênese e desenvolvimento de um fato científico", o teste de Wassermann para identificar a sífilis. Ele descreve minuciosamente as hesitações do destino diante das diversas direções na construção de um fato científico antes de fixar-se em uma situação estável. “Após 15 anos, todavia, aconteceu uma identificação dos resultados com as intenções com o pensamento de Wassermann. O zigue-zague do desenvolvimento, cujas etapas todos certamente acompanharam com muita atenção, converteu-se num caminho reto e consciente de sua meta... Os protagonistas da ação não têm mais como nos ensinar como esse processo se deu: racionalizam e idealizam o caminho" (Fleck, [1935]2010:123).

Quase 50 anos depois de Fleck, Bruno Latour e Steve Woolgar estudaram etnograficamente, acompanhando no laboratório do Instituto Salk na Califórnia a realização da gênese e do desenvolvimento da caracterização do TRF (Thyrotropin Releasing Factor - fator (hormônio) de liberação da tirotropina), um fato científico que rendeu o Prêmio Nobel de Medicina a Roger Guillemin. "Um fato é reconhecido como tal quando perde todos os seus atributos temporais e integra-se em um vasto conjunto de conhecimentos edificados por outros fatos. Quando se pretende escrever a história de um fato, esbarra-se em uma dificuldade essencial: ele perdeu, por definição, qualquer referencial histórico" (Latour; Woolgar, [1979] 1997:101-102).

Sharon Traweek estudou a comunidade de físicos de partículas de alta energia. Na prática e na teoria esses cientistas pesquisam, utilizando equipamentos que custam bilhões de dólares, os componentes básicos do universo. Ela mostrou que a constituição e o comportamento das partículas subatômicas de alta energia no "mundo das coisas-em-si", definidos no campo da física, dependem de diferenças nos esquemas de financiamento de pesquisa nos EUA e no Japão, que acontecem no "mundo dos humanos-entre-si", definidos no campo da política, na segunda metade do século XX (Traweek, 1988). 
Estes são somente três exemplos eloquentes de como os conhecimentos científicos são feitos, em contraposição à existência de um mundo da Ciência idealizado.

O conhecimento resulta de um processo de subsequentes tarefas de criar, colher e justapor elementos heterogêneos, de subsequentes "idas a campo", sejam esses campos interações em sítios remotos, verificações com colegas ou jornadas diante de instrumentos de laboratório, e subsequentes apreciações nos "centros de cálculo" para onde são sucessivamente levados os elementos colhidos nessas "idas a campo". Reconhecer a aquisição de conhecimento sobre o vírus como um processo de subsequentes entrevistas com médicos e infectologistas, idas a hospitais, visitas a doentes, verificando as proezas do vírus, cartografando a sua disseminação e analisando o que é obtido nessas "idas a campo" nos ajuda a reconhecer que o "vírus" que vamos encontrar não é algo que "está lá" como um objeto ou uma situação isolável, mas sim algo, "objeto" ou situação, que vai adquirindo uma forma em sua própria interação conosco nessas sucessivas "idas a campo" e análises em nossos centros de cálculo. Lidar com o vírus é abrir um caminho que, ao ser percorrido, constrói o vírus. Não existe, portanto, uma "realidade do vírus" como algo que "está lá", existente a priori, sobre a qual poderíamos falar e tomar decisões coletivamente independente de quem queira conhecê-la e agir sobre/com ela ${ }^{5}$.

Metáforas beligerantes como "combater o vírus inimigo" são muito úteis para mobilizar as pessoas e podem ir muito longe politicamente. Mas podem ser enganosas se tomadas como indicadoras da existência a priori de determinados lugares ou situações que podem ser descobertos e mapeados onde o "vírus" pode ser encontrado como "em si mesmo", como em sua forma pura (Shapin, 2010; 2013).

De modo geral, as/os cientistas reconhecem que a Ciência resulta do debate constante, de perguntas e hipóteses bem definidas e do cuidadoso exame dos processos utilizados, mas logo quase todos acrescentam que "a ciência busca a verdade", sem esclarecer que espécie de verdade é essa que a ciência busca. Dizer simplesmente que "a ciência busca a verdade" dá continuidade à alegoria moderna da ciência como universal, neutra e objetiva, e à crença de que a ciência é apolítica. Desde meados do século XX, no entanto, as verdades da antropologia, da sociologia e da história da ciência mostram que os conhecimentos científicos, como todos os conhecimentos, são "situados", valem em seus enquadramentos, isto é, suas verdades têm valor de verdade em culturas, lugares e tempos específicos (não são universais), atuam a favor ou contra pessoas e coisas (não são neutros), e não captam uma realidade objetiva independente de uma concepção prévia da realidade (não são objetivos).

\footnotetext{
5 A expressão "ida a campo" relaciona-se diretamente à descrição de coleta de "inscrições" em Latour ([1987] 1997:355-377 - Cap. 6 - Parte A). Para um admirável texto ressonante local ver Bachtold (2017).
} 
Fazendo um parêntesis, dizer que todo conhecimento é situado significa que todo conhecimento se configura em um enquadramento, um recorte de uma realidade preconcebida, por assim dizer - esse é um resultado epistemológico dos Estudos de Ciências-TecnologiasSociedades (CTS em português e STS em inglês) das últimas décadas (Haraway, 1988; Haraway, 2000). Além disso, todo enquadramento tem transbordamentos, isto é, partes do mundo que não entraram no enquadramento em que se configurou um conhecimento (Callon, 1998). Não se enxerga a população brasileira sem um poderoso instrumento, por exemplo, o IBGE. Da mesma forma, a Covid-19 é algo que não pode ser visto sem que para isso se construa um poderoso instrumento. Se bem construído, o conhecimento que esse instrumento nos proporcionará será válido e verdadeiro, no sentido de ser robusto e confiável, mas sempre estritamente dentro dos enquadramentos adotados em sua construção. Cabe ressaltar o caráter dinâmico dos enquadramentos e transbordamentos, pois no universo aberto do mundo haverá sempre possibilidades que serão deixadas fora do mundo fechado do enquadramento que situa um conhecimento científico. Ou seja, o que é e o que deixa de ser relevante ou preocupante varia no espaço e no tempo.

Daí a importância de focalizar especialmente os enquadramentos adotados na construção de conhecimentos sobre a Covid-19. Das opções e das delimitações, do que entra ou deixa de entrar nos enquadramentos adotados resulta mais do que a representação, resulta a própria constituição do que vem a ser o "vírus na população brasileira" como algo coletivo e discutível.

Fechando o parêntesis, durante a segunda metade do século XX, foram retirados das verdades das ciências os predicados de universalidade, neutralidade e objetividade que até então lhes eram atribuídos sem mais qualificações, de forma absoluta. A Ciência perdeu o "C" maiúsculo e ganhou o "s", saí a Ciência e entram em cena as ciências. Nada irrita mais os cientistas do que esse grau de relativismo justaposto às verdades científicas. Mas calma! Não vamos tampouco cair em outra armadilha, "a armadilha retórica do construtivismo sociológico radical, cuja tragédia afeta não só a inteligência como também, em casos de pandemia, a própria sobrevivência pessoal" (Lacerda, 2020:82).

Recapitulando, continuar dizendo que "a ciência busca a verdade", sem dar maiores explicações sobre "que verdade é essa", serve para que as relações entre ciência e política, que sempre existiram, permaneçam invisíveis. Enxergar essas relações é crucial para a qualidade do uso das ciências na composição/negociação da governança para uma zona de contato. Ao não situar os conhecimentos científicos na cultura, nas suas consequências, e na versão preconcebida de realidade em que foram gerados e desenvolvidos, a parte escolarizada da população irá crer 
saber e impor aos outros como eles devem viver "fortalecida em sua tarefa pela segurança que apenas a Ciência pode oferecer" (Polanyi, [1944] 2000:154).

Ao serem revelados como conhecimentos "situados", e terem os processos, opções, decisões, condições de criação, afetos, valores, e modos-de-vida ${ }^{6}$ que os criaram e os sustentam explicitados e abertos a questionamentos, dois deslocamentos incidem sobre os conhecimentos científicos: (1) eles não perdem seu valor, mas os enquadramentos do mundo, os recortes de espaço e tempo, as condições em que são validos passam a fazer deles, como etiquetas que especificam as características de um produto que está na prateleira de uma loja; (2) eles ganham a historicidade das obras humanas. Em outras palavras, eles passam a resultar de atividades para as quais as perguntas onde? quando? por quê? por quem? para quê? para quem? precisam ser colocadas com e para os coletivos culturais e geográficos compostos em uma variedade de repúblicas ou povos que discutem como querem ser governados, usando-os em busca da governança de um mundo parcialmente comum.

Os conhecimentos científicos têm validade, e continuam sendo válidos, nos enquadramentos construídos, acordados e adotados em suas gêneses e em seus desenvolvimentos. Situar o conhecimento científico não o invalida, mas mostra que sua validade vigora estritamente nos enquadramentos estabelecidos no seu desenvolvimento. Os conhecimentos científicos não podem ser simplesmente transladados para fora dos enquadramentos escolhidos em sua gênese e desenvolvimento, embora seja essa, infelizmente, a atitude prevalente em meio àqueles resignados em sua situação de colonizados pela Ciência (e mesmo também pelas ciências) do homem branco, que se veem e se identificam equivocadamente na imagem do colonizador. E aí, para nós, brasileiros, talvez esteja a ironia das consequências da virada antropológica dos estudos de laboratório porque essa relativização do conhecimento científico corresponde a uma relativização do conhecimento de nossos colonizadores euro-americanos. Os conhecimentos científicos podem, sem garantia de sucesso, ser traduzidos dos enquadramentos em que foram criados para enquadramentos em outros espaços, tempos, culturas e povos, mas isso requer o trabalho de reconstruir, ou seja, transladar / traduzir / trair os conhecimentos científicos. Não é possível desenvolver aqui esse tema da translação / tradução / traição nos estudos de ciências-tecnologias-sociedades ${ }^{7}$ (Law, 1994). Esse tema é, no entanto, sem sombra de dúvida, crucial para avaliar a educação e a criação de conhecimento no Brasil a partir da relação do Brasil com suas raízes e suas metrópoles. Como,

\footnotetext{
${ }^{6}$ Optei por "modos-de-vida" por me parecer uma expressão mais comunicativa do que "modos-de-existência" que teria como vantagem incluir as coisas nos coletivos de humanos e coisas das repúblicas (Souriau, 2009; Latour, 2012; 2013).

${ }^{7}$ Ver, por exemplo, Law (1994).
} 
quais e de que maneira podemos na diversidade brasileira selecionar, aceitar, modificar, resistir aos conhecimentos trazidos, por um lado, de nossas próprias raízes (e dos aqui enraizados) e, por outro, de nossas metrópoles? ${ }^{8}$

\section{$O$ "X" da questão}

As últimas décadas do século XX distanciaram-se da epistemologia dos séculos anteriores e consolidaram esse "relativismo realista" das ciências (Law; Hassard, 1999). Cada conhecimento científico é válido no enquadramento que faz e em que, em co-construção, é feito, refeito e se situa. $\mathrm{E}$ aqui talvez nos aproximemos do $\mathrm{X}$ da questão das relações entre conhecimentos científicos e outros conhecimentos, especialmente a autoridade dos conhecimentos científicos frente a asserções espantosas e indignantes sobre a COVID-19 e outras que nos chegam e transitam em zonas de contato onde também transitam os conhecimentos científicos.

Não creio que possamos ter garantia de boas respostas para questões que envolvem governança em busca de um mundo parcialmente comum. Especialmente aqui, talvez, os acontecimentos podem se antecipar às boas respostas para as questões que suscitam. No que tange aos conhecimentos científicos, boas respostas, para mim, seriam aquelas respostas conducentes à produção de saberes científicos a favor de muitos e não de poucos, respostas conducentes a saberes científicos a favor da preservação da diversidade e contra políticas do eliminar ou deixar morrer que toleram ou mesmo levam a ciências fascistas. Sem garantias de sucesso e malgrado as dificuldades que já podemos antever, uma condição para a obtenção de boas respostas, sempre situadas, é, creio, colocar os enquadramentos para criação, aceitação, modificação, e resistência aos conhecimentos científicos para discussão e decisão por um público que não se restrinja aos próprios cientistas. Em outas palavras, $o X$ da questão é superar $o$ período histórico em que, escudados em mundos imaginados e na epistemologia euro-americana ainda dominante (“mainstream”), os cientistas só aceitavam discutir em seus próprios termos".

\footnotetext{
${ }^{8}$ Estudiosos do encontro do Japão com a modernidade no século XIX, registram que "precisamente porque os japoneses não aceitaram sempre a presunção ocidental de uma relação unilinear certificando desenvolvimento progressivo e sucessão que [no Japão] o discurso sobre o moderno foi capaz de prover uma gama de sanções para tanto a resistência às exigências da razão 'universal' mascarando um etos imperial ocidental quanto para a rendição a ele" (Miyoshi; Harootunian, 1989:XVII).

9 "O debate entre os pesquisadores da Cloroquina, independente de postura favorável ou contrária ao seu uso, seja em que fase for, é claramente demarcado: de um lado, os pesquisadores, vendo qual a melhor ciência para o povo; de outro, o povo, a massa (quase um rebanho, mesmo?) que será tratado. Os primeiros estão autorizados a falar; os segundos, sem vozes, devem ouvir e aguardar, posto que não estão legitimados a emitir opinião" (Rodrigues, 2020:152).
} 
Em termos euro-americanos, eticamente, a retirada do privilégio epistemológico das ciências equipara o saber (o modo de vida) do supremacista branco ao saber (o modo de vida) de qualquer outro povo. Saber fabricar armas e mercadorias modernas pode instituir acachapantes assimetrias, mas, eticamente, não dá ao homem branco, ou a quem saiba, o direito de dizer aos outros como eles devem viver.

O modo de vida de um Yanomami ou de um berlinense, eticamente, não vale nem mais nem menos um do que o outro ${ }^{10}$. Nenhum dos dois tem o direito de dizer ao outro como ele deve viver. A retirada do privilégio epistemológico do modo de vida euro-americano fertiliza o diálogo entre os saberes, entre os modos de vida no mundo. Mais berlinenses são agora mais abertos para ouvir um intelectual ameríndio e lhe dar razão. No começo do século XXI, já não soa tão estranho para o berlinense ouvir de um escritor ameríndio que "[a]té o começo do século $\mathrm{XX}$, o mundo do trabalho e da produção (o mundo do homem branco) se dava com ferramentas e meios que não tinham a potência de exaurir os recursos da Terra como hoje" (Krenak, 2020, p:72). Esse ponto de encontro pode levar a outros e, quem sabe, a asserção desse mesmo escritor, "O rio Doce, que nós, os Krenak, chamamos de Watu, nosso avô, é uma pessoa, não um recurso, como dizem os economistas" (Krenak, 2019:40), transladada / traduzida / traída / negociada em diálogo, um dia venha a ser um fato para ambos?

Uma vez acordado o respeito ético de não invasão às partes não compartilhadas como uma espécie de enquadramento primevo, será preciso estendê-lo, traduzindo-o, para estabelecer a governança nas zonas de contato. É justamente aí que se dão os encontros e, portanto, teoricamente, as "inevitáveis invasões", pois é justamente aí que os modos de vida diferentes se entremeiam sem fronteiras previamente definidas. A governança nas zonas de contato diz respeito à construção de fronteiras. As zonas de contato não são regiões de fronteiras necessariamente geográficas, embora possam sê-lo em certos casos. Elas podem localizar-se em espaços não contíguos, com modos de vida diferentes que se entremeiam em espaços urbanos e rurais, habitando o mesmo espaço geográfico. Aqui interessa-nos especialmente as zonas de

\footnotetext{
${ }^{10}$ Sabemos que não é essa a opinião das corporações que governam o mundo. Para elas o valor de uma vida humana é o potencial daquela vida como produtora e consumidora de mercadorias. Um exemplo chocante, por ter sido tão explícito, foi o cálculo da indenização das vítimas do acidente que é considerado o maior acidente industrial da história, em 3 de dezembro de 1984 em Bhopal, Índia, quando explodiu uma fábrica da Union Carbide (depois comprada pela Dow Chemical) espalhando 40 toneladas do gás letal metil isocianeto, matando milhares de pessoas. A indenização acordada após muita resistência das empresas foi de US\$2.220,00 para cada família totalizando US\$ 470 milhões. Tivesse esse acidente ocorrido nos EUA e os valores fossem os mesmos da compensação a americanos obtida no caso do amianto em que a mesma Union Carbide foi condenada, o valor seria cerca de US\$10 bilhões. Para o "povo da mercadoria" a vida de um americano médio que produz e consume 20 vezes mais do que um indiano médio vale, portanto, 20 vezes mais. Veja um relato detalhado do acidente e suas consequências em Broughton (2005). Ver também Friedman (2020).
} 
contato entre pessoas com modos de vida cientificamente informados e pessoas que não se submetem aos argumentos científicos.

\section{Cuidado com as evidências}

A evidência, como algo que se dá a conhecer a alguém, somente continuará evidente nos enquadramentos (muitas vezes invisíveis ou inconscientes) em que se evidenciou. Para que uma evidência se torne parte do conhecimento de um coletivo de pessoas e coisas, é preciso que esse coletivo compartilhe os enquadramentos da evidência ${ }^{11}$. $\mathrm{O}$ exame rigoroso dos enquadramentos passa então ao primeiro plano quando se busca estabelecer governanças éticas em zonas de contato a partir de evidências. A explicitação dos enquadramentos tem sempre limites, chegando aos limites da própria linguagem. Esse é um terreno movediço em que o político e o técnico se imbricam inextricavelmente. Os acordos só serão possíveis se preponderar entre as partes o entendimento de que as condições e as consequências dos enquadramentos foram suficientemente examinadas e ponderadas e de que, se algo não previsto se apresentar, será preciso novamente reunir as partes. Do contrário, cada desconfiança e cada controvérsia não terminará.

A raiz latina de evidência (e-videre) nos lembra de trazer à tona o que está para ser visto. Mas nem tudo o que pode ser feito para trazer o que pode ser visto é sempre feito. Tomadas de posição baseadas em evidências podem insistir em descrever, compilar e analisar experiências anteriores - o que aconteceu, com quais recursos, para quem, com qual resultado - mas quando e se o fazem, o fazem sempre necessariamente selecionando e estreitando a base do que pode vir a ser uma evidência. Não há como escapar disso, o que é evidente é evidente somente para quem está usando determinados óculos que filtram e impregnam certos tons ao que é visto.

Há óculos com tonalidades que dificultam enxergar as tais boas respostas; por exemplo, ao supervalorizar a disponibilidade presente de métodos e privilegiar desmedidamente somente o que pode ser imediatamente medido. Ao pretender enxergar o mais longe possível este tipo de óculos lança sua rede baseada em evidências o mais amplamente possível, insistindo que tudo pode ser comparado, ao mesmo tempo em que seleciona cuidadosamente as unidades de comparação $^{12}$. Esse processo é uma prática que reduz e aplaina as contingências e as

\footnotetext{
${ }^{11}$ Creio que, por exemplo, no caso de evidências científicas, não seja difícil concordar que no mundo radicalmente especializado em que vivemos o que é evidente para uma pessoa ou para os especialistas de um determinado campo pode estar longe de continuar sendo evidente quando apresentado a leigos ou a outros especialistas e a evidência é muitas vezes contestada. Em um mundo cientificizado, isto resulta, muito prosaicamente, do fato de que especialidades diferentes geralmente adotam enquadramentos diferentes para seus fatos, teorias, objetos e sujeitos.

${ }^{12}$ Uma medida é, em última instância, sempre uma comparação.
} 
peculiaridades locais, constrói enquadramentos padronizados e os resultados são considerados mais "objetivos" (Nowotny, 2007). Estes óculos têm, como se espera, a preferência dos police makers, gestores e gerentes escolarizados que enfatizam que "somente o que pode ser medido pode ser gerenciado" invocando "pragmatismo".

Por outro lado, retirado o absolutismo das auras de universalidade, neutralidade e objetividade, os inimigos dos conhecimentos científicos estão sempre epistemologicamente autorizados e se sentem mais confiantes a inspecionar os enquadramentos para estabelecer “controvérsias". Os enquadramentos envolvem condições de medida, escolhas das inscrições, definição de dados, contabilidade, limites, hipóteses e omissões, e aí pode-se procurar as limitações e os erros que estariam incorporados aos conhecimentos científicos, agora reconhecidos como resultantes desse processo vulnerável.

E, é preciso deixar claro, a direita, os poderosos, os brancos supremacistas saíram na frente aproveitando a perda do privilégio epistemológico absolutista da Ciência, como podemos perceber desde as asserções sobre o que fazer diante da exploração dos recursos naturais, dados os limites do planeta, até aquelas sobre as qualidades da cloroquina. Com expedientes, será sempre possível abrir controvérsias e seguir duvidando de um conhecimento científico e das/os cientistas que os produziram. Ou seja, corremos o risco de jogar fora o bebê do conhecimento científico na água suja do banho do absolutismo (da universalidade, neutralidade e objetividade) da Ciência.

O privilégio epistemológico aumentava a autoridade dos conhecimentos científicos, facilitava a sua naturalização, tornando os enquadramentos invisíveis e os conhecimentos científicos mais difíceis de serem fragilizados. Mas dotar os cientistas do poder despótico de únicos criadores e detentores do conhecimento confiável, é esse o ponto a que chegou a modernidade euro-americana com seus especialistas, é acreditar que os cientistas sejam déspotas esclarecidos ou, como Merton, que sejam encarnações de um bom mocismo idealizado. Além disso, é desqualificar os não cientificamente escolarizados como capazes de integrar a produção de conhecimento com visões mais amplas de como viver melhor. Para se buscar as boas respostas para a governança das zonas de contato é preciso, não há mais dúvida, reconhecer as reduções cognitivas e ontológicas postas em prática pelas ciências. Mas, por outro lado, dar livre percurso aos "mercadores da dúvida", equiparando-os àqueles que genuinamente vivem outros modos de vida, é capitular na busca de novas governanças pois as controvérsias abertas pelos "mercadores da dúvida" têm precisamente a finalidade de retirar as ciências das arenas políticas.

É neste momento que se torna claro que decisões sobre onde, quando, com que e para que, com quem e para quem, fazer ciências não é assunto exclusivo dos cientistas. Para termos 
legitimidade, e por consequência apoio robusto para os fazeres científicos no Brasil, ${ }^{13}$ é preciso ter essas perguntas sejam democrática e republicanamente postas, discutidas e respondidas nas zonas de contato entre os modos de vida presentes em nosso país, que incluem levas de gente para muito além de nossa casta escolarizada, e os modos de vida daqueles que atuam como agentes mais simplórios da colonização euro-americana.

Sem dúvida, as/os cientistas no Brasil precisam repelir enfaticamente o namoro e o casamento de Jair Bolsonaro, para usar suas metáforas preferidas, com a implantação de um regime autoritário em nosso país. Mas é necessário ter humildade para ir além. Isso é ainda mais urgente em tempos de pandemia e de escassez de recursos. Se buscamos o diálogo para a construção de governanças em nossas zonas de contato, devemos começar pela humildade reconhecendo que os conhecimentos científicos e a razão herdada de nossas metrópoles não têm um privilégio epistemológico, mas são simplesmente uma dentre uma infinidade de possibilidades.

Sobram espanto e indignação, mas os conhecimentos científicos não conseguem se impor ao criacionismo, ao terraplanismo, e à receita da cloroquina. Mas não seria o caso de mudarmos os enquadramentos para facilitar a separação entre os "mercadores da dúvida" e aqueles que genuinamente resistem à colonização pelas ciências e desejam simplesmente viver como querem?

\section{Mudando os enquadramentos}

Vejamos bem, a perda do privilégio epistemológico concede aos conhecimentos científicos, agora ontologicamente mais modestos, um espaço de tolerância e indiferença. No caso da asserção “a cloroquina cura a COVID 19”, um contingente módico de cientistas e médicos a defenderam como um fato científico. A asserção, no entanto, foi adotada por atores poderosos que a apoiaram e ampliaram a sua circulação como fato científico. E isso nos leva a outro resultado crucial decorrente da virada antropológica nos estudos de ciências-tecnologiassociedades: no espectro fato-ficção, o destino de uma asserção depende do que "os outros" fazem com ela. Não cabe mais (só) aos cientistas decidir sobre o destino de uma asserção, isso depende dos "outros", depende do que os "outros" fazem com ela. Ou seja, atores que não são cientistas participam da estabilização das asserções nas condições de ficção ou de fato, inclusive na estabilização (sempre provisional) dos fatos científicos, principalmente se as asserções

\footnotetext{
${ }^{13}$ Para uma crítica da avaliação que a CAPES, o CNPq, as agências estaduais de modo geral fazem dos afazeres dos programas de pós-graduação no Brasil, ver Da Costa Marques (2019).
} 
mobilizam pessoas e coisas em grande escala. A noção antes vigente de que nem a religião, nem o governo, nem o povo participavam do estabelecimento de fatos científicos foi deslocada. Se atores não cientistas participam da estabilização de uma asserção como fato científico, então as alianças dos cientistas para defender os fatos científicos devem necessariamente ser negociadas também com atores não cientistas.

Por exemplo, se perguntados, vamos, simplificadamente e com razão, dizer que "a Terra não é plana". E, se desafiados, apresentaremos os argumentos e as provas da redondeza da Terra. A razão e a lógica desses argumentos e provas, no entanto, são aderentes a um modo de vida e vão convencer justamente os que têm as razões e as lógicas das ciências incorporadas a seus modos de vida. Nós vamos convencer, por assim dizer, os que já estão convencidos. Entretanto, são precisamente os afetos dessa razão, que não é única, que estão em questão. Essa razão pode não mobilizar os "outros" que pensam e vivem um modo de vida diferente, acolhem e dão destino a outras asserções. Para esses “outros", talvez a experiência de jogar bola em um campo plano lhes seja determinante.

Se você for um engenheiro calculando as distâncias voadas entre duas cidades, é preciso que você esteja convencido de que a Terra não é plana. Ou se você se espantar ao falar com um amigo que viajou para Lisboa e quiser saber por que a hora lá é diferente da hora no Rio, é bem possível que você seja mais facilmente convencido de que a Terra não é plana. Mas se nada disso acontece e você não quiser ser engenheiro, você pode muito bem jogar futebol, dirigir um carro e até tomar um avião sem que esse conflito com o outro conhecimento - o conhecimento científico estabilizado, o de que a Terra é redonda - lhe atravesse o caminho. Dessa forma, o desafio aqui será o dos cientistas abdicarem do seu impulso colonial (dizer como os outros devem viver), arriscarem-se e afirmarem-se, ou não, situada e politicamente caso a caso na materialidade e no interesse de cada caso.

O reenquadramento da questão da autoridade dos conhecimentos científicos requer reconceitualizar e reposicionar, situar as fronteiras entre o tecnocientífico e o político, trabalhando nas especificidades de cada caso de maneira não universal, mas particular (crítica à separação sujeito/objeto); não neutra, mas com afetos (crítica à separação Natureza/Sociedade); não objetiva mas situada (aberta à discussão das versões preconcebidas de realidade onde o conhecimento em pauta atua, e não trazendo a realidade euro-americana como o enquadramento último em que se decidirá a legitimidade do conhecimento por verificação de adesão a ela, sem reconhecer ela própria como uma versão preconcebida de Realidade).

$\mathrm{Na}$ busca das boas respostas não se ignora o conhecimento pós mertoniano de que os enquadramentos e os próprios conhecimentos não são neutros, eles atendem a certas demandas e 
mobilizam certos interesses. Justamente porque estar controvertida a questão da administração da cloroquina poder matar uma pessoa, então a decisão de onde, quando, a quem, e por quem a cloroquina pode ser administrada não deveria ser só dos cientistas e médicos, mas deveria ser balizada em coletivos de humanos e não humanos compostos em repúblicas que decidiriam sobre o uso da cloroquina para seus próprios cidadãos e não para os outros. Este seria um outro enquadramento da questão. Já antevejo as dificuldades que serão apontadas para definir e fazer valer as fronteiras dessas novas repúblicas. Mas não esqueçamos que as fronteiras, divisões, categorias, e cidadanias de hoje decorrem do que foi contingente em certos acordos iniciais que se naturalizaram.

\title{
Comentário final
}

Nossas metrópoles já há mais de duas décadas pragmaticamente se ocupam com a demanda imediata do $\mathrm{X}$ da questão: quem deve ser incluído para suplementar o papel dos cientistas (especialistas) na construção de conhecimentos? Devemos estar atentos aos encaminhamentos metropolitanos, até porque, dada a "colonialidade do poder" prevalecente no Brasil, a tendência será seguir os caminhos que os EUA e a Europa traçarem. Lá, no entanto, não parece haver preocupações com modos de vida diferentes dos padrões euro-americanos que nortearam a colonização do Brasil, especialmente a partir do século XIX. Pelo contrário, os caminhos sugeridos não parecem buscar como integrar um mundo de comunidades de diversos modos de vida e sim como incorporar os saberes dos não especializados para consolidar, intensificando ainda mais, o já hegemônico modo de vida do "povo da mercadoria". Sheila Jasanoff assim apresenta um número especial do periódico Science and Public Policy, de Abril de 2004:

\begin{abstract}
A relação entre ciência e cidadania é hoje objeto de uma discussão ativa nos processos de construção da identidade social, incluindo a identidade do cidadão como produtor e consumidor de conhecimento; a fusão de consumo e cidadania por meio do uso de transações de mercado para promover formas particulares de conhecer o mundo; e o trabalho de conhecimento politicamente relevante, com os cidadãos complementando o papel de especialistas. Os artigos desta edição especial exploram como, em cada contexto, instituições poderosas, como estados e corporações, estão lutando para definir princípios pelos quais determinar quais cidadãos devem ser incluídos, e em quais termos, em decisões e debates relevantes (Jasanoff, 2004:90).
\end{abstract}

Mesmo que sejam enormes as dificuldades para a construção ética de um mundo parcialmente comum, a tarefa se justifica, uma vez que a alternativa que se vê no horizonte é "a barbaria que se aproxima" (Danowski; Viveiros De Castro, 2015; Stengers, 2015; Latour, 2018). 


\section{Referências}

BACHTOLD, Isabele V. (2017), Precisamos encontrá-los!" Etnografia dos números do Cadastro Único e dos cruzamentos de base de dados do governo federal brasileiro. 167f (Mestrado). Departamento de Antropologia, Universidade de Brasília, Brasília, DF.

BIJKER, Wiebr E.; HUGHES, Thomas P.; PINCH, Trevor J. (1987), The social construction of technological systems: new directions in the sociology and history of technology. Cambridge, Mass, MIT Press.

BROUGHTON, Edward (2005), "The Bhopal disaster and its aftermath: a review". Environmental Health: A Global Access Science Source, n. 6, pp. 1-6 [Consult. 19-07-2021]. Disponível em http://www.ehjournal.net/content/4/1/6

CALHOUN, Ccraig (2010). Robert K. Merton: sociology of science and sociology as science. New York, Columbia University Press.

CALLON, Michael (1988), The laws of the markets. Oxford; Malden, MA, Blackwell Publishers/Sociological Review.

DA COSTA MARQUES, Ivan (2019), "Novos elementos para avaliar a avaliação da CAPES", in L. P. Rodrigues; J. Almeida; G. B. Coelho (Orgs.). Ciência, Interdisciplinaridade e Avaliação CAPES. Jundiaí, SP, Paco Editorial, pp.159-192.

DANOWSKI, Débora; VIVEIROS DE CASTRO, Eduardo (2015), Há um mundo por vir? Ensaio sobre os medos e os fins. Florianópolis, Desterro; Cultura e Barbárie; Instituto Socioambiental.

FLECK, Ludwik ([1935] 2010). Gênese e desenvolvimento de um fato científico - introdução à doutrina do estilo de pensamento e do coletivo de pensamento. Belo Horizonte, Fabrefactum.

FRIEDMAN, Howard S. (2020), Ultimate Price: The Value We Place on Life. Oakland, CA, University of California Press.

HARAWAY, Donna (1988), "Situated Knowledges: The Science Question in Feminism as a Site of Discourse on the Privilege of Partial Perspective". Feminist Studies, v. 14, n. 3, pp. 575-599 [Consult. 24-07-2021]. Disponível em https://doi.org/10.2307/3178066

HARAWAY, Donna (1991), Simians, cyborgs, and women: the reinvention of nature. New York, Routledge.

HARAWAY, Donna J. (2000), "Manifesto ciborgue: ciência, tecnologia e feminismo-socialista no final do século XX", in D. Haraway; H. Kuzru; T. Tadeu (Orgs.). Antropologia do ciborgue - as vertigens do pós-humano. Belo Horizonte, Autêntica Editora, pp.37-129.

JASANOFF, Sheila (2004), "Science and citizenship: a new synergy". Science and Public Policy, v. 31, n. 2, pp. 90-94 [Consult. 20-07-2021]. Disponível em https://doi.org/10.3152/147154304781780064

KNORR-CETINA, Karin (1981), The manufacture of knowledge: an essay on the constructivist and contextual nature of science. Oxford, New York, Pergamon Press.

KOPENAWA, Davi; ALBERT, Bruce (2015), A queda do céu: palavras de um xamã yanomami. São Paulo, SP, Companhia das Letras.

KRENAK, Ailton (2019), Ideias para adiar o fim do mundo. São Paulo, Companhia das Letras. 
KRENAK, Ailton (2020), A vida não é útil. São Paulo, Companhia das Letras.

LACERDA, Marcos (2020), "Governança na pandemia: a ciência como regulação moral e os problemas da biopolítica”. Simbiótica. Edição Especial, v. 7, n. 1, pp. 69-83 [Consult. 22-07-2021). Disponível em https://periodicos.ufes.br/index.php/simbiotica/article/view/30983

LATOUR, Bruno ([1987]1997), Ciência em Ação - Como seguir cientistas e engenheiros sociedade afora. São Paulo, UNESP.

LATOUR, Bruno (2012), ENQUÊTE SUR LES MODES D'EXISTENCE - une anthropologie des Modernes. Paris, La Découverte.

LATOUR, Bruno (2013), An inquiry into modes of existence: an anthropology of the moderns. Cambridge, MA, Harvard University Press.

LATOUR, Bruno (2018), Down to earth: politics in the new climatic regime. Cambridge, UK; Medford, MA: Polity Press, 1 online resource.

LATOUR, Bruno; WOOLGAR, Steve ([1979]1997), A vida de laboratório - a produção dos fatos científicos. Rio de Janeiro, Relume Dumará.

LATOUR, Bruno; WOOLGAR, Steve (1986), Laboratory life: the construction of scientific facts. Princeton, Princeton University Press.

LAW, John (1994), Organizing modernity. Oxford, UK, Cambridge, Mass., USA, Blackwell.

LAW, John; HASSARD, John (1999), Actor network theory and after. Oxford England, Malden, MA, Blackwell/Sociological Review.

LYNCH, Michael (1985). Art and artifact in laboratory science: a study of shop work and shop talk in a research laboratory. London; Boston, Routledge \& Kegan Paul.

MARCOVICH, Anne; SHINN, Terry (2011), "Robert K. Merton: between a universalist vision of science and a procrustean framework (entre uma visão universalista da ciência e uma estrutura fechada do conhecimento". Revista Brasileira de História da Ciência, v. 4, n. 1, pp. 26-32 [Consult. 22-07-2021]. Disponível em https://www.sbhc.org.br/arquivo/download?ID_ARQUIVO=19

MIYOSHI, Masao; HAROOTUNIAN, Harry D. (Eds.) (1989), Postmodernism and Japan. Durham, Duke University Press.

MERTON, Robert K. (1970), Sociologia: teoria e estrutura. São Paulo, Mestre Jou.

NASCIMENTO, Kamila (2020), “Covid-19: a globalização do infortúnio”. Simbiótica. Edição Especial, v. 7, n. 1, pp. 39-52 [Consult. 20-07-2021].

Disponível em https://periodicos.ufes.br/simbiotica/article/view/30981

NOWOTNY, Helga (2007), "How Many Policy Rooms are There? Evidence-Based and Other Kinds of Science Policies". Science, Technology \& Human Values, v. 32, n. 4, pp. 479-490 [Consult. 19-072021]. Disponível em https://doi.org/10.1177/0162243907301005

POLANYI, Karl ([1944]1999). A Grande Transformação - as origens da nossa época. Rio de Janeiro, Editora Campus.

PRATT, Mary L. ([1992]1999), Os olhos do império: relatos de viagem e transculturação. Bauru, SP, EDUSC. 
RODRIGUES, Léo P. (2020), "A controvérsia científica em torno da cloroquina e hidroxicloroquina no tratamento da Covid-19: a importância dos estudos sociais da ciência na sociedade complexa". Simbiótica. Edição Especial, v. 7, n. 1, pp. 147-171 [Consult. 20-07-2021]. Disponível em https://periodicos.ufes.br/simbiotica/article/view/30988

RUFINO, Luiz (2019), Pedagogia das encruzilhadas. Rio de Janeiro, Mórula Editorial.

SAHLINS, Marshall (2008), The Western Illusion of Human Nature: With Reflections on the Long History of Hierarchy, Equality, and the Sublimation of Anarchy in the West, and Comparative Notes on Other Conceptions of the Human Condition. Chicago, Prickly Paradigm Press 2008.

SHAPIN, Steven ([2010]2013). NUNCA PURA. Estudos Históricos da Ciência como se ela fora produzida por pessoas com corpos, situadas no tempo, no espaço, na cultura e na sociedade e que se empenham por credidibilidade e autoridade. Belo Horizonte, Fino Traço Editora.

SOURIAU, Étienne (2009), Les différents modes d'existence. Paris, Presses Universitaires de France.

STENGERS, Isabelle (2015), No tempo das catástrofes - resistir à barbárie que se aproxima. São Paulo, Cosac Naify.

TRAWEEK, Sharon (1988), Beamtimes and lifetimes: the world of high energy physicists. Cambridge, Mass. Harvard University Press. 


\begin{abstract}
The Science Studies showed that scientific knowledges are historical results of human activities, abandoning the illusion of scientific knowledge as universal, neutral, and objective in an absolute way. This opened, on the one hand, new possibilities for peaceful coexistence with "modes-of-existence" foreign to the sciences, but, on the other hand, opportunities for denialisms. The difficulty is that the abandonment of the illusion aimed at strengthening and not weakening scientific knowledge, but it provided permanent opportunities for the opening of controversies. Then, execrable "merchants of doubt" appeared, who, with resources, bet on the disqualification of scientific knowledge and scientists. How to deal with the end of the absolutist illusion of Science and not throw away scientific knowledge? That is the question I intend to address.
\end{abstract}

Keywords: science; denialisms; knowledge; euro-american.

\title{
Resumen
}

Los estudios sociales de las ciencias y tecnologías, al mostrar el conocimiento científico como obra humana, abrieron, por un lado, nuevas posibilidades de convivencia pacífica con "formas-de-vida" ajenas a las ciencias, pero, por otro lado, oportunidades de negación. La dificultad es que el abandono de la ilusión del conocimiento científico como universal, neutral y objetivo de manera absoluta apunta a fortalecer y no debilitar el conocimiento científico. Pero el fin de la ilusión brindó oportunidades permanentes para la controversia. Entonces aparecieron execrables "mercaderes de la duda" que, con recursos, apostaron por la descalificación del saber científico y de los científicos. ¿Cómo afrontar el fin de la ilusión absolutista de la ciencia y no desechar el conocimiento científico? Ésa es la pregunta que pretendo abordar.

Palabras clave: ciencia; negacionismos; conocimiento; euroamericano. 